\title{
The Folded Conformation of Perezone Revisited. Long Range nOe Interaction in Small Molecules: Interpretable Small Signals or Useless Large Artifacts?
}

\author{
Elizabeth Reyes-López, ${ }^{1}$ Beatriz Quiroz-García, ${ }^{1}$ Pablo Carpio-Martínez, ${ }^{1}$ Jesús Jiménez-Barbero, ${ }^{2,3}$ \\ Fernando Cortés-Guzmán, ${ }^{1}$ Nuria Esturau-Escofet, ${ }^{1}$ and Gabriel Cuevas*1 \\ 1 Departamento de Fisicoquímica, Instituto de Química, Universidad Nacional Autónoma de México. Circuito Exterior, \\ Ciudad Universitaria, C.P. 04510, Coyoacán, México City, México. \\ 2 Infectious Disease Program, CIC bioGUNE, Parque Tecnológico de Bizkaia, Building 801A, 48160 Derio, Spain. \\ 3 IKERBASQUE, Basque Foundation for Science, 48011 Bilbao, Spain. \\ * Corresponding author: e-mail: gecgb@unam.mx; phone number: +52 555622 4770/46608.
}

December 14 ${ }^{\text {th }}, 2016$; Accepted February $24^{\text {th }}, 2017$.

\begin{abstract}
The nuclear Overhauser effect (nOe) is a consequence of the cross-relaxation and it involves the transfer of nuclear spin polarization from one population to another intra or inter-molecularly. It is generally accepted that a proton-proton distance between 4 and $5 \AA$ is the upper limit for the occurrence of measurable nOe's in small molecules. However, we herein show how detectable nOe's may, in fact, take place between alkyl groups of quinones with substitutions at 1-4 relative positions, showing distances longer than $6 \AA$. Although the signals of interest are very small, of the order of $1 \%$ of a normal nOe, so a priori are considered artifacts originated by decoupling modulation, they maintain, properties that make them interesting and give them coherence as interpretable signals. If the signals of interest are not artifacts these observations represent an important breakthrough with impact on the standard protocols that are commonly used for determination of molecular structure and conformation.

Keywords: NOE; conformational analysis; $\pi / \pi$ interactions; hydrodynamic radii; NMR spectroscopy.
\end{abstract}

\section{Introduction}

The nuclear Overhauser effect (nOe) has long been used to determine molecular conformation, configuration and stereochemistry [1,2]. It is well known that intermolecular distances can be estimated from the cross relaxation rates between two spins, since this is proportional to the inverse of the sixth power of the internuclear distance $\left(\mathrm{r}^{-6}\right)$ [3]. Cross-relaxation, which also depends on molecular motion, can be obtained by the build-up curve of the nOe as a function of mixing time. The related formalisms, as well as the corresponding methods have been described $[1,3,4,5]$.

Due to the $\mathrm{r}^{-6}$ and motional dependence, the nOe quickly decreases with the distance for small molecules and it is generally accepted that a distance between 4 to $5 \AA$ is the limit for the effect to be detected $[1,2]$. At very short correlation times the maximum achievable nOe enhancement is small in magnitude, because the dipole dipole relaxation mechanism is weak. Under normal conditions for nOe mixing time employed varies
Resumen. El efecto Nuclear de Overhauser (nOe) es una consecuencia de la relajación cruzada, la cual implica la transferencia de polarización de un spin nuclear a otro, ya sea intra o intermolecularmente. Generalmente se acepta que el límite para su detección en moléculas pequeñas es aquel en el que los protones interactuantes se encuentran a una distancia entre 4 y $5 \AA$ A. Sin embargo, aquí mostramos, como estos nOe's pueden existir entre grupos alquilo en posiciones 1-4 de quinonas sustituidas, a distancias mayores a $6 \AA$. Si bien, las señales de interés son muy pequeñas, del orden del $1 \%$ de un nOe normal, por lo que a priori se les considera artefactos, originadas en "modulación de desacoplamiento" estas mantienen, extrañamente, propiedades que las hacen interesantes y les dan coherencia como señales interpretables. De no ser artefactos, estas observaciones representan un avance importante con impacto en los protocolos estándar comúnmente empleados para la determinación de la estructura y conformación molecular.

Palabras clave: nOe; análisis conformacional; interacciones $\pi / \pi$; radio hidrodinámico; espectroscopía de RMN.

between $500-800 \mathrm{~ms}$ and for ROE between $300-500 \mathrm{~ms}$, and long-range nOe, beyond $5 \AA$ are not observable. Nevertheless, some cases have been described and some of these weak nOes were observed and used for structural purposes [6]. Since these signals can be quite relevant from the structural and conformational standpoint, it is important to rigorously establish their nature.

For large molecules, the motional dependence permits the detection of nOes at a longer distance [7]. Indeed, for the determination of the structure of proteins in solution, distance restrictions based on nOe intensities are a key step to perform the molecular optimization $[8,9,10]$. Similar approaches may be adapted for small and medium size molecules. Since this protocol is based on the correlation of known distances with their corresponding nOe intensities, it is extremely important to establish and document abnormal cases, such as that presented herein.

An artifact is a signal that does not have any physicochemical sense. It is a factor that affects the correct interpretation of 
a result. In NMR, an artifact is a senseless signal that can be originated by several factors such as the manipulation of a sample, the uncertainty of a determination, and the manipulation or transformation of the spectra. It can also be originated by electronical issues with the instruments used to make the determination. Artifacts are characterized by their variability and inconsistent reproducibility. Depending on the sample, artifacts can be intensified or disappear in different regions of the spectrum or show multiplicities that cannot be interpreted.

From the chemical perspective, the presence of double bonds in remote position in quinones has a remarkable influence in their structure and reactivity properties. For instance, in perezone [11], the first natural product isolated and described in America by Leopoldo Rio de la Loza in 1852 [12], (1a, Fig. 1) the double bond in remote position influences the formation of $\beta$ (2a) and $\alpha$-pipitzol (2b) (Fig. 2). Calculations at the MP2/6-31G(d,p) and MP2/6-31++G(d,p)//MP2/6-31G(d,p) levels determined that folded conformers $(\mathbf{1} \mathrm{b}$ and $\mathbf{1 c})$ are minima in the potential energy surface (PES) and that the inclusion of electronic correlation is fundamental to correctly represent this system. In fact, when using HF and B3LYP theoretical methods, unable to include large distance interaction terms, the folded conformers $(\mathbf{1 b}$ and $\mathbf{1 c})$ turned out to be less stable than the extended ones (such as 1a or 1d). The existence of conformers depends on the level of theory.

The presence of folded structures has been commonly used as argument to describe relevant properties of similar quinones, such as the series of ubiquinones Q1-Q10 [13]. This study addresses perezone and some of its derivatives in order to determine if the observed signals can have analytical relevance or not; and, if relevant, further advance the understanding of their origin.

\section{Results and Discussion}

Initially, the double-pulsed field gradient nOe pulse sequence (DPFGSE-NOE) was used since this is the most widely used selective nOe experiment [14]. For this case, samples were analyzed in a $500 \mathrm{MHz}$ spectrometer at $25^{\circ} \mathrm{C}$ in a chloroform solution, using $800 \mathrm{~ms}$ as the mixing time value and $\mathrm{D} 1=1 \mathrm{~s}$ (Fig. 3). These are the parameters included in the commercial<smiles>CC(C)=CCC[C@H](C)C1=C(O)C(=O)C(C)=CC1=O</smiles>

$1 \mathbf{a}$<smiles>CC1=CC(=O)C(C(C)C)=C(O)C(=O)C1C(=O)C(C)C</smiles>

$1 \mathbf{b}$<smiles>CC1=CC(=O)C([C@H](C)CC[C@@H](C)CC(=O)C2=C(O)C(=O)C(=O)C=C2C)=C(O)C1=O</smiles>

1c

\section{1d}

Fig. 1. Some conformers of perezone (1).

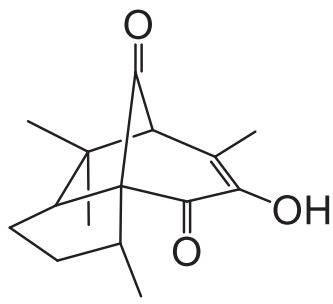

2a

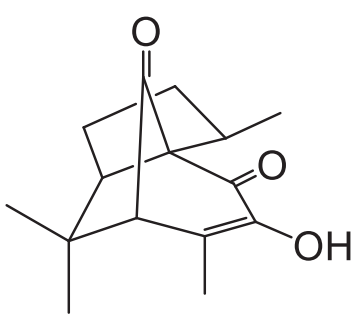

2b

Fig. 2. $\alpha$ (2a) and $\beta$-pipitzol (2b). 


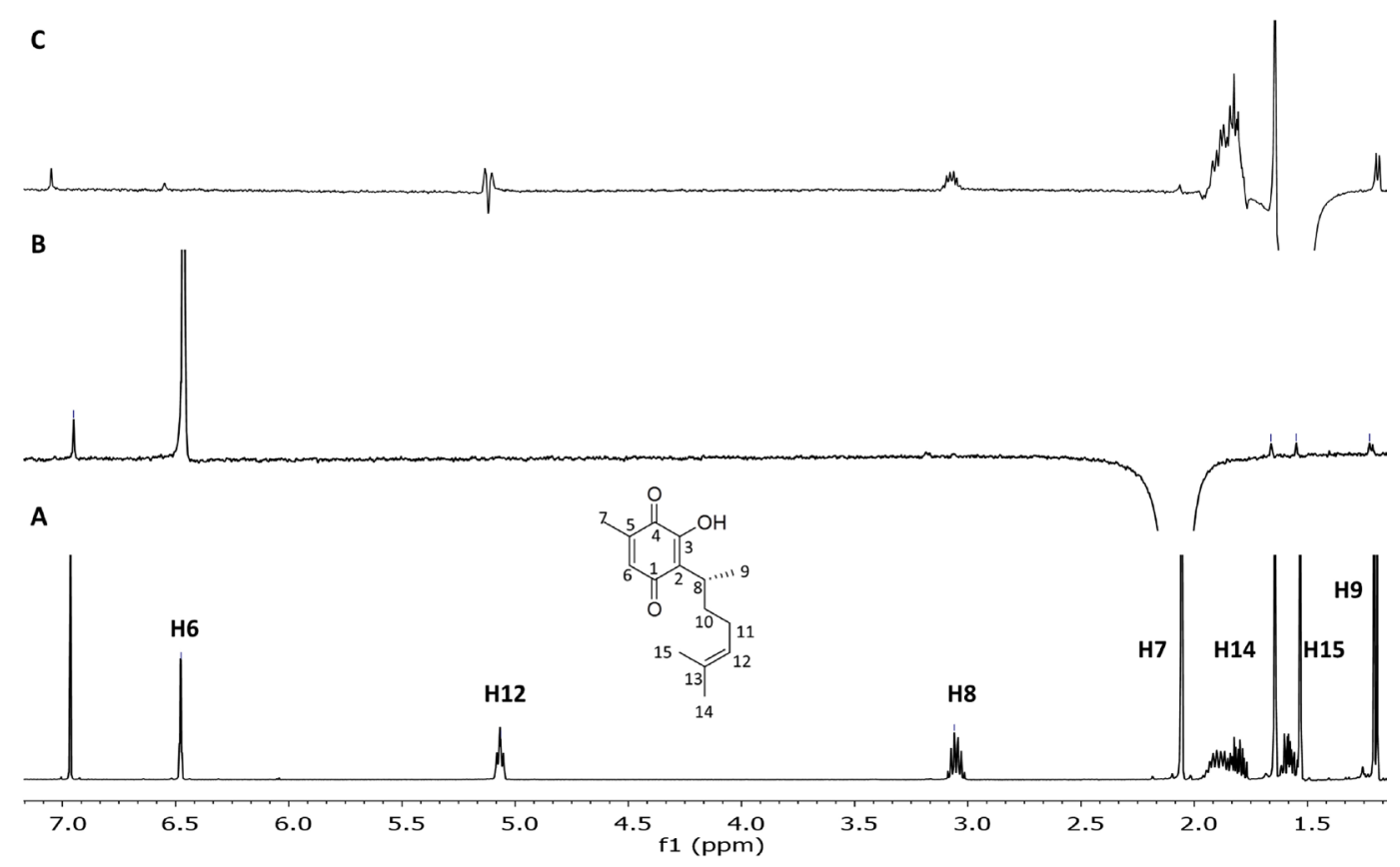

Fig. 3. (A) $500 \mathrm{MHz}^{1} \mathrm{H}$ spectrum of perezone (1) in $\mathrm{CDCl}_{3}$; (B-C) $1 \mathrm{D}-\mathrm{DPFGSE}-\mathrm{NOE}$ spectra using a mixing time of $800 \mathrm{~ms}$, $\mathrm{nt}=4096$, D1 $=1 \mathrm{~s}$ (B) selective inversion of $\mathrm{H} 7$, (C) selective inversion of $\mathrm{H} 15$.

software and are designed to observe the signals of interest under the conditions normally used for this type of analysis. When the signal for methyl $\mathrm{H} 7$ attached to the quinone was irradiated (B, Fig. 3) a normal $\mathrm{H} 6 \mathrm{nOe}$ effect $(1.01 \%)$ is observed along with the weak signals of methyls H14 $(0.02 \%)$ and H15 $(0.02 \%)$, of the isopropylene group. These signals are easily distinguished (ratio signal:noise $=4$ ). This warrants the presence of the folded conformer. The observation of signals $\mathrm{H} 8$ $(0.02 \%)$ and $\mathrm{H} 9(0.03 \%)$, located at a distance of more than $6 \AA$ is also relevant. However, questions arise since the irradiated area is broad and includes the signals of H10 and H11, thus, the latter can be considered normal nOes. It is pertinent to note that the nOes measured in this work are relative to the signal that is irradiated. The magnitude of this reference signal is enormous. In this context, the signal corresponding to the vicinal nOe is $1 \%$, which is small. However, the signal-to-noise ratio of the smallest signals presented in this work is at least 2 and reaches up to 5 .

Interestingly, the irradiation on the methyl group H15 resonance (C, Fig. 3) allowed the observation of nOes on $\mathrm{H} 6$ and $\mathrm{H} 7(0.02 \%)$, as well as a trivial nOe at its neighbor H14 (1.01\%) and $\mathrm{H} 12(0.06 \%)$. Additional nOes were observed at H8, H9, and with the $\mathrm{OH}$ moiety. These effects may be easily explained by the torsion of the alkyl chain. The intense nOes with diasterotopic protons $\mathrm{H} 10$ and $\mathrm{H} 11$ are also trivial.

It is important to point out that the coupling constants experienced by each of the protons involved are observed in the nOe difference spectrum. These constants are measurable from the spectra. For example, for hydrogen $\mathrm{H} 9$ in the normal spectrum a value of ${ }^{3} \mathrm{~J}_{\mathrm{H}-\mathrm{H}}=7.0 \mathrm{~Hz}$ is obtained, and in the nOe spectrum it is of $7.0 \mathrm{~Hz}$.
Due to the flatness and rigidity of the quinone ring, the atoms that produce these small nOes are far in space; outside the generally accepted limits for nOe observation.

Considering the molecular geometries determined at M06$2 \mathrm{X} / 6-31++\mathrm{G}(\mathrm{d}, \mathrm{p})$ level of theory (Fig. 4), the closest interatomic distances vary with the relative orientation of the alkyl chain and oscillate between 6.6 and $6.7 \AA$ for the protons of methyl $\mathrm{C} 7$ and the proton of methine $\mathrm{C} 8$, and between 5.7 and 6.9 for the protons joined to methyl $\mathrm{C} 7$-methyl $\mathrm{C}$ 9. The relative stability of the folded conformers is remarkable as determined at the MP2/6-31(d,p) level [11].

For the $\mathrm{OH} / \mathrm{H} 6$ and $\mathrm{OH} / \mathrm{H} 7$ nOes, the distances between the protons involved are between 4.6 and $4.7 \AA$, when the $\mathrm{OH}$ forms a hydrogen bond with the carbonyl group, at the upper limit for nOe observation. The detection of several "non-typical" nOes for proton pairs well beyond these distances requires further investigation.

Fig. 5 shows the obtained nOes using a different pulse sequence (selnogp5.cga) at $20^{\circ} \mathrm{C}$ in an instrument of $700 \mathrm{MHz}$ [15], the concentration was decreased to $0.02 \mathrm{M}$ to preclude the presence (if any) of significant dimer formation. Even at this low concentration, clear nOes between remote protons were observed, similar to those observed at the higher concentration $(0.08 \mathrm{M})$. For instance, when the position $\mathrm{H} 7$ was irradiated, weak nOe's with H14 and H15 (0.1 and 0.09\%), associated with the presence of folded conformers were measured. Besides trivial contacts, additional nOes were observed at $\mathrm{H} 6(0.84 \%)$ and the $\mathrm{OH}$ group $(0.14 \%)$. Interestingly, these small signals do not change with the shift in concentration and are maintained with different samples. There are no changes with neither the chemical shift nor the multiplicity and there is no change when 

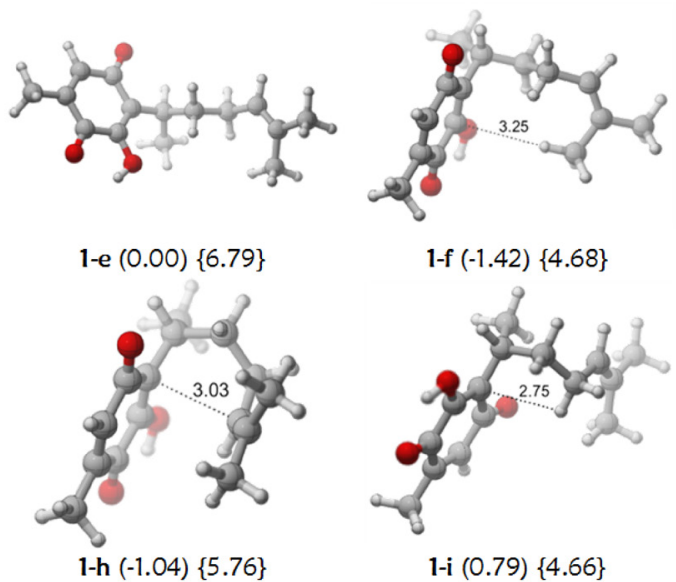

1-i (0.79) $\{4.66\}$

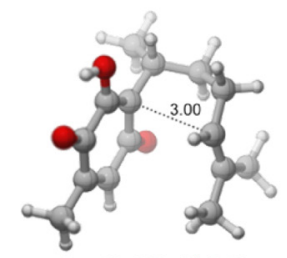

$1-g(2.97)\{5.98\}$

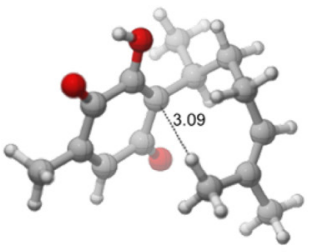

1-j $(-2.73)\{4.97\}$

Fig. 4. Some conformers of Perezone (1) at the M06-2X/6-31++G(d,p) level. The relative stabilities are presented in parentheses $(\mathrm{kcal} / \mathrm{mol})$ and the hydrodynamic radii in brackets $(\AA)$.

different instruments with different frequencies are used. Thus, it is considered that these signals do not seem to be artifacts.

A summary of the results for O-methylperezone (3) is shown on Fig. 6. The presence of folded conformers in the conformational equilibrium was also conclusively revealed from the observed nOes. Interestingly, the absence of the $\mathrm{OH}$ group should decrease the polarization of the quinone's carbonyl group and thus, its ability to accept charge from the olefin in the folded conformers [16].

For instance, when $\mathrm{H} 7$ is irradiated (B, Fig. 6) weak nOes with H14 and H15 methyl groups were observed. When H6 was irradiated, (C, Fig. 6), nOes were detected at H14 and H15, further confirming the presence of folded conformers. Even more, nOes at H8, H9 and the methyl group were also evident.

Additional experiments were performed in different solvents of different nature, DMSO- $\mathrm{d}_{6}$ and acetonitrile- $\mathrm{d}_{3}$. Therefore, regardless the solvent's polarity and viscosity, the folded conformers participate in the conformational equilibrium. Interestingly, nOe's for distant protons, at distances longer than 6 $\AA$, are clearly observed (Fig. 7).

\section{Intra or inter-molecular nOe.}

A plausible explanation could be the presence of intermolecular nOes through the formation of dimer structures. Several
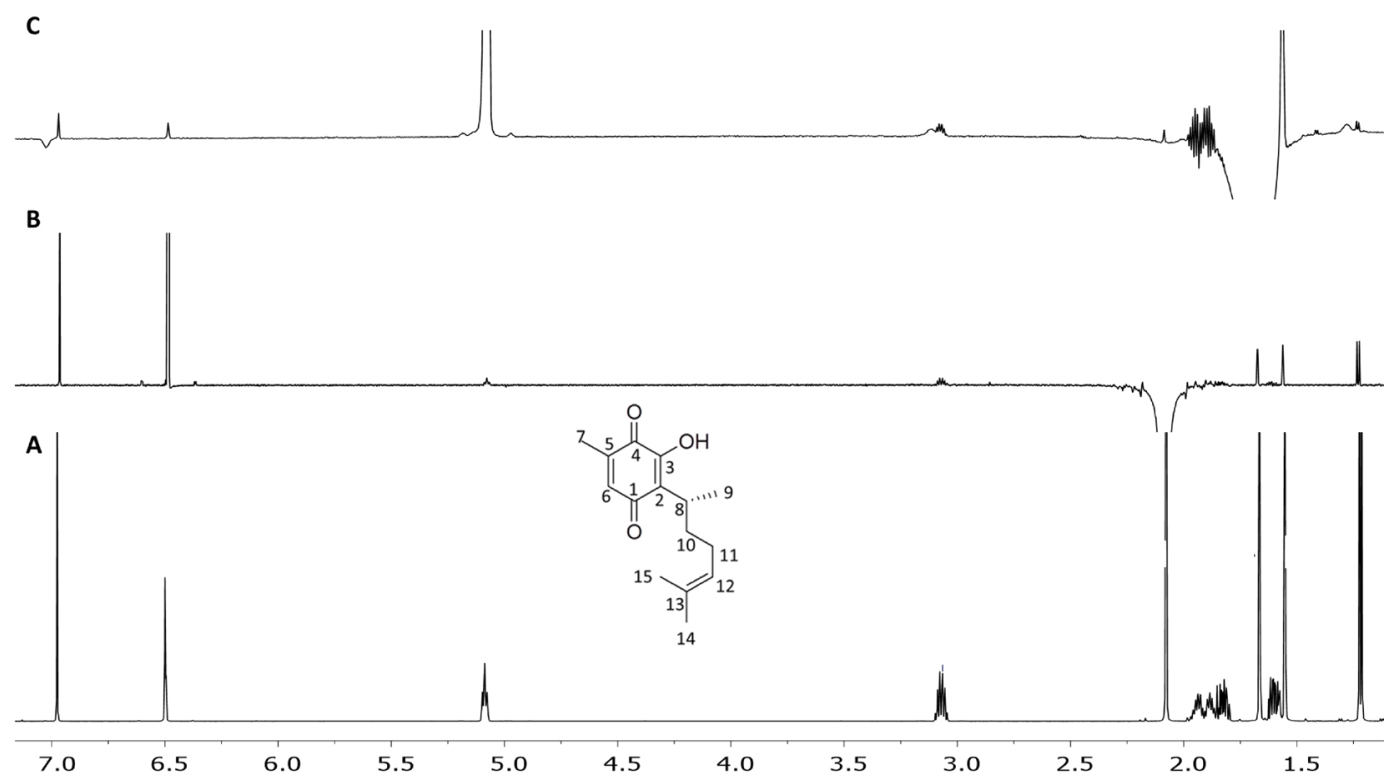

Fig. 5. (A) Conventional 700-MHz ${ }^{1} \mathrm{H}$ spectrum of Perezone (1) in $\mathrm{CDCl}_{3}$; (B-C) 1D selnogp5.cga spectra using a nOe mixing time of 800ms, selective inversion of: (B) H7, (C) H14. 


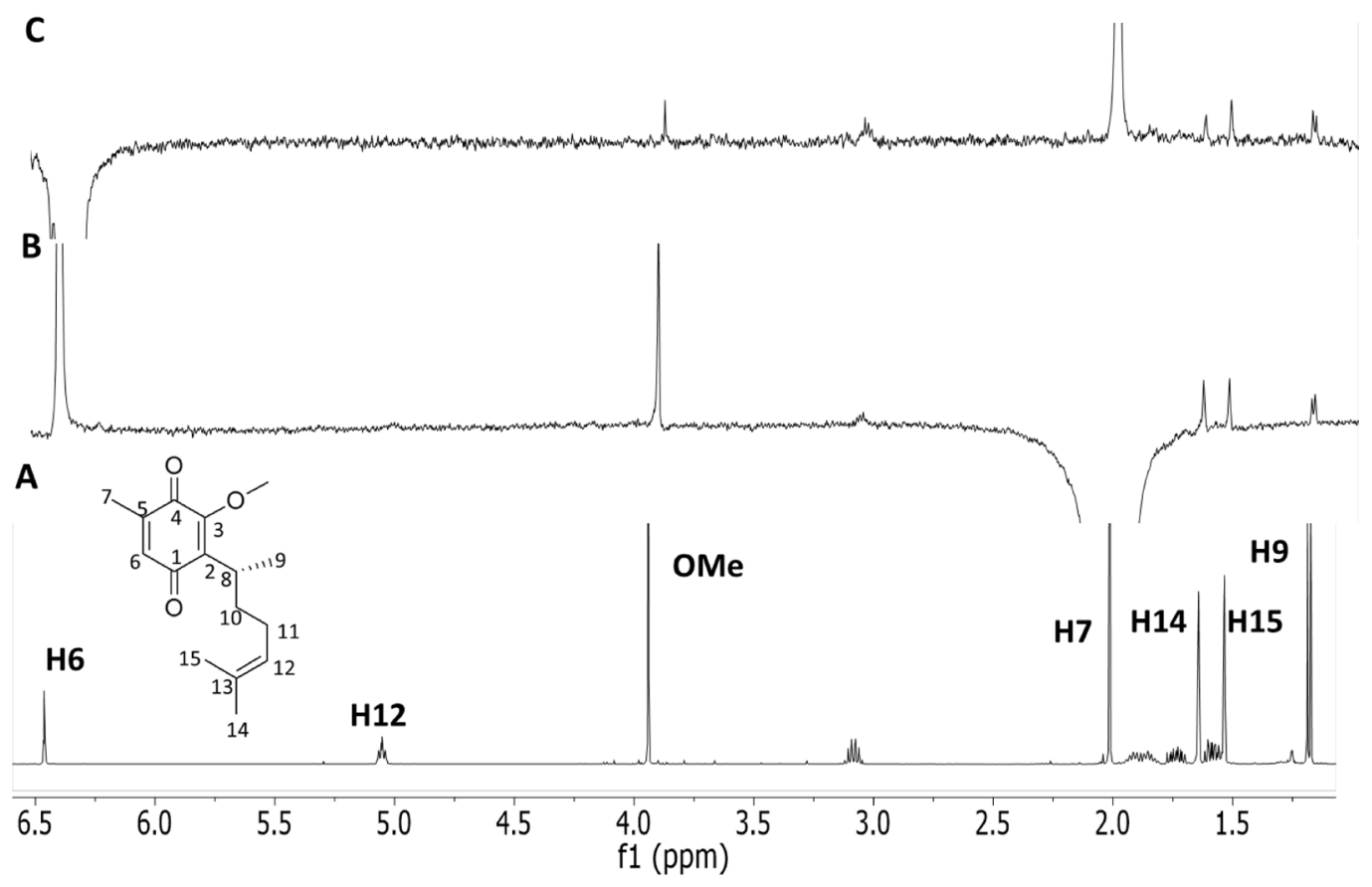

Fig. 6. (A) Conventional 500-MHz ${ }^{1} \mathrm{H}$ spectrum of O-methylperezone (3) in $\mathrm{CDCl}_{3}$; (B-C) 1D DPFGSE-NOE spectra using a nOe mixing time of $800 \mathrm{~ms}$, selective inversion of (B) $\mathrm{H} 7$ and (C) H6.

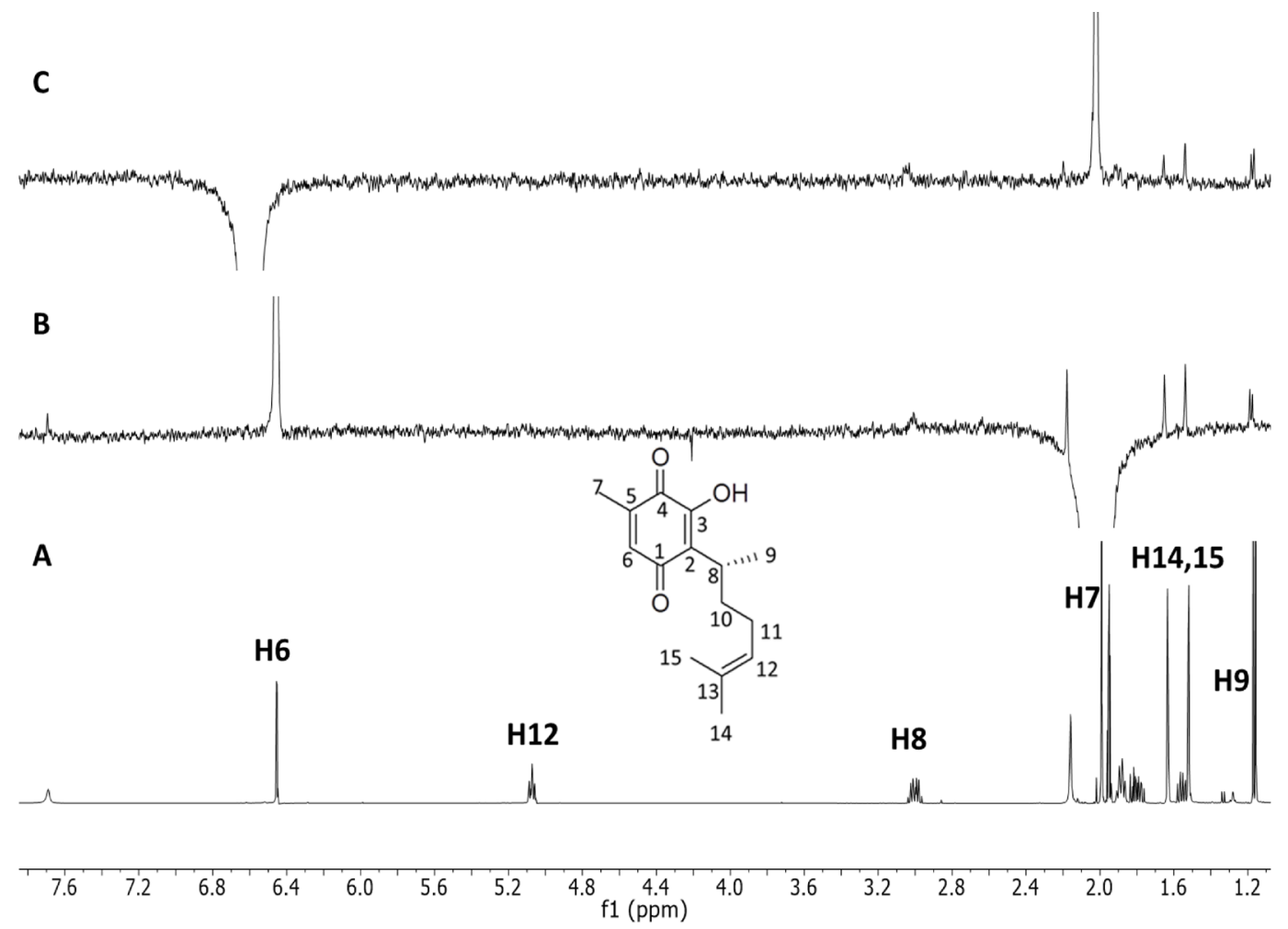

Fig. 7. (A) Conventional 500-MHz ${ }^{1} \mathrm{H}$ spectrum of perezone (1) in acetonitrile-d $\mathrm{d}_{3}$; (B-C) 1D DPFGSE-NOE spectra using a nOe mixing time of $800 \mathrm{~ms}$, selective inversion of (B) H7 and (C) H6. 
putative arrangements (Fig. 8) were considered that produce different interaction energies. The most stable arrangement combines double bond-quinone and quinone-quinone interactions; while the least stable exclusively incorporates double bond-quinone interactions. The hydrodynamic radius of the dimers varied between 6.5 and $7.8 \AA$. The putative existence of a perezone dimer in solution (Table 1) could account for the existence of the observed nOe.

From inspection of Table 1, there is a reasonable agreement between the predicted intermolecular distances for the putative dimers and the magnitude of the observed nOe.

The possibility of dimer formation was further explored by measuring the diffusion coefficient of the species. DOSY experiments have been extremely useful to verify the formation of ligand-receptor or molecule/molecule complexes, since the diffusion coefficients of the involved species are altered as consequence of the formation of the complex [17]. TMS was employed as internal reference, with a hydrodynamic radii (HR) of 2.48 A. (Table 2).

At the M06-2X/6-31++G(d,p) level of theory, TMS displays a hydrodynamic radius of $2.48 \AA$ [18] in full agreement with Berger's value [17] Then, the effective hydrodynamic radius of the different molecules under study was estimated. The values of the diffusion coefficient in DMSO-d6 were, in all cases, lower than those determined in cyclohexane-d12, indicating a higher level of solvent-solute interactions (hydrogen bonds) in the first solvent. (Table 2).

The experimental HR of $p$-cymene $(\mathbf{5}$, Fig. 9) in cyclohexane is $2.85 \AA$, while in DMSO is $3.06 \AA(\Delta \mathrm{HR}=0.21 \AA)$. The theoretical calculation predicts a larger size in the vapor phase, of $4.25 \AA$, possibly originated from the effect of the condensed phase. Herein, the space generated by the HR is fully filled by a single solute molecule. This value can be considered

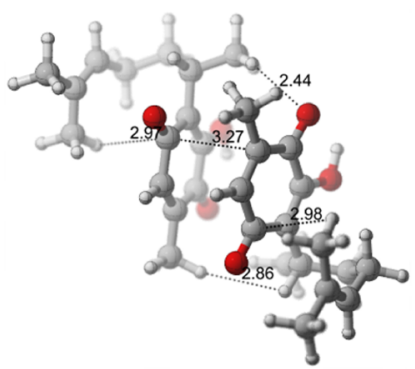

D1-a $(0.00)[-11.07]\{7.33\}$

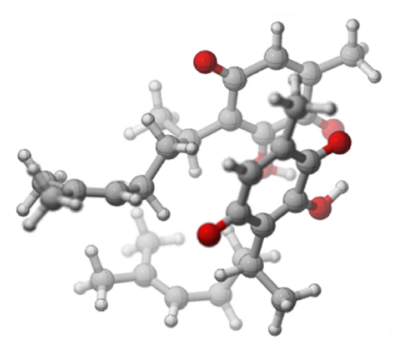

D1-c (1.63) $[-9.44]\{6.91\}$

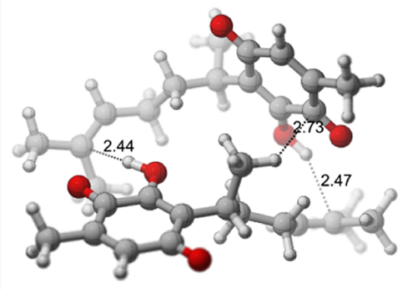

D1-e (4.06) [-7.01] $\{7.33\}$

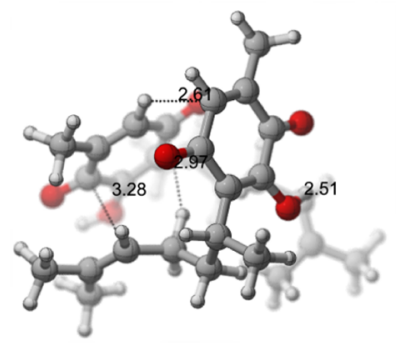

D1-b (0.41) [-10.66] $\{6.50\}$

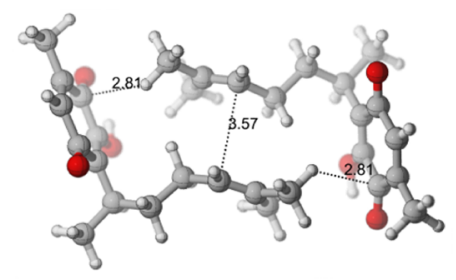

D1-d (2.68) [-8.39] \{7.79\}

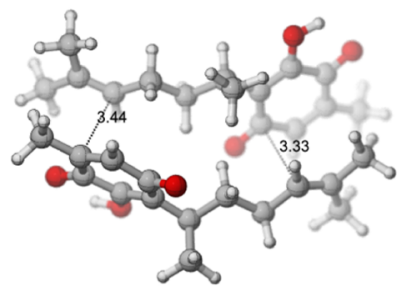

D1-f (5.86) $[-5.21]\{7.15\}$
Fig. 8. Some dimeric arrangements of perezone (1). The relative stabilities are presented in parentheses, interaction energies in brackets ( $\mathrm{kcal} / \mathrm{mol})$ and the hydrodynamic radii in braces $(\AA)$, calculated at M06-2X/6-31++G(d,p) level of theory.

Table 1. Relevant inter-atomic distances $(\AA)$ for the two dimeric arrangements D1-b and D1-f of interacting Perezone molecules (Figure 8$)$ at M06-2X/6-31++G(d,p) level of theory. The relevant intra and inter molecule and ensemble average $<\mathrm{r}^{6}>$ proton-proton distances were estimated from the integration of the observed nOe's (measured in selective nOe experiments with mixing times of 600,800 and $1000 \mathrm{~ms}$ ) using the ISPA approximation.

Calculated distance for each dimer $(\AA)$

\begin{tabular}{lcccc}
\cline { 2 - 3 } Atom Pair & Dimer D1-b & Dimer D1-f & Observed nOe Intensity & Experimental Distance $(\AA)$ \\
\hline H6 H12' & 4.0856 & 5.0919 & Weak & 3.9 \\
H6 H8' & 4.7861 & 6.3139 & Medium & 3.4 \\
H6 H14, & 5.5325 & 4.1688 & Weak & 3.9 \\
H6 H15' & 6.0908 & 5.5681 & Medium weak & 3.6 \\
H6 H9' & 6.3431 & 4.4160 & Medium weak & 3.6 \\
H7 H14, & 2.3146 & 2.3378 & Medium weak & 3.6 \\
H7 H15, & 4.2874 & 2.2401 & Medium & 3.5 \\
H12 H8 & 4.2594 & 4.5599 & Strong & 2.9 \\
H12 H9 & 5.2542 & 4.6847 & Weak & 4.0 \\
\hline
\end{tabular}


Table 2. Diffusion coefficient of perezone (1), O-methylperezone (3), thymoquinone (4), p-cymene (5) and a synthetic intermediate of perezone (6) determined by DOSY. Calculations were done at M06-2X/6-31++G(d,p) level of theory using continuum salvation model (SMD) with acetonitrile as a solvent.

\begin{tabular}{|c|c|c|c|c|c|c|c|}
\hline \multirow[b]{3}{*}{ Compound } & \multirow{3}{*}{$\begin{array}{c}\mathrm{D}_{\text {DMSO }} \\
\left(10^{10} \mathrm{~m}^{2} \mathrm{~s}^{-1}\right)\end{array}$} & \multirow{3}{*}{$\begin{array}{l}\mathrm{D}_{\text {cyclohexane }} \\
10^{10}\left(\mathrm{~m}^{2} \mathrm{~s}^{-1}\right)\end{array}$} & \multirow{2}{*}{\multicolumn{2}{|c|}{$\mathrm{D} / \mathrm{D}_{\mathrm{TMS}}$ Coefficient }} & \multicolumn{3}{|c|}{ Hydrodynamic radii } \\
\hline & & & & & \multicolumn{2}{|c|}{ Experimental } & \multirow[t]{2}{*}{ Theoretical } \\
\hline & & & $\mathrm{DMSO}^{-\mathrm{d}_{6}}$ & $\mathrm{C}_{6} \mathrm{~d}_{12}$ & DMSO-d $_{6}$ & $\mathrm{C}_{6} \mathrm{~d}_{12}$ & \\
\hline Perezone (1) & 2.75 & 7.29 & 0.437 & 0.571 & 5.67 & 4.34 & $6.5-7.8$ \\
\hline OMe-Perezone (3) & 3.15 & 7.06 & 0.501 & 0.550 & 4.95 & 4.50 & \\
\hline Thymoquinone (4) & 4.39 & 10.1 & 0.717 & 0.767 & 3.45 & 3.23 & 4.25 \\
\hline p-cymene (5) & 5.12 & 11.6 & 0.811 & 0.870 & 3.06 & 2.85 & 4.25 \\
\hline Coupled product (6) & 2.78 & 6.15 & 0.454 & 0.488 & 5.46 & 5.16 & \\
\hline TMS & 6.28 & 12.7 & 1 & 1 & 2.48 & 2.48 & 2.48 \\
\hline
\end{tabular}

as reference for the case of a solvated isolated molecule. In thymoquinone (4, Fig. 9), a similar pattern was observed. In DMSO, the association is larger than in cyclohexane (HR values are 3.45 and 3.23 , respectively, with $\Delta \mathrm{HR}=0.22 \AA$ in the second). The value of HR is similar to that theoretically calculated for compound 5. These numbers suggest that this molecule is not associated, but individually solvated.

Compound 6 (Fig. 9), similar to p-cymene (5), is unable to self-associate with another molecule or to produce folded arrangements because of double bond-aromatic interactions. Therefore, it is expected that the extended conformation should be dominant. In fact, the difference between the HR as a function of solvent $(\Delta \mathrm{HR}=0.30 \AA)$ is larger than in the previous cases. The calculated HR value only allows including a single molecule in the associated space.

For perezone (1), the difference between the HR value in both solvents is largely increased $(\triangle \mathrm{HR}=1.33 \AA)$. This is a proof of hydrogen bond formation in DMSO. In this solvent, HR is $5.67 \AA$, larger than the value for $\mathbf{6}$, the reference for extended conformers. On the other hand, the value of HR of 1 in cyclohexane is $4.34 \AA$, smaller than the value of $\mathbf{6}$. This fact suggests that folded conformers significantly participate in the conformacional equilibrium. The HR calculated for some perezone conformers (1) are shown in Fig. 4, ranging from $6.8 \AA$ to $4.7 \AA$ for the extended and folded conformers. These numbers<smiles>CC1=CC(=O)C(C(C)C)=CC1=O</smiles>

4

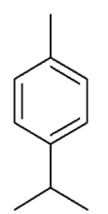

5

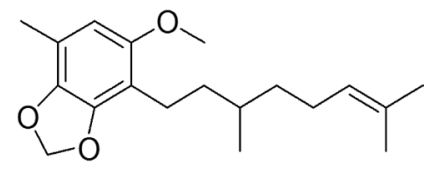

6
Figure 9. Structures of thymoquinone (4), p-cymene (5) and coupled product (6). strongly suggest that only a single molecule occupies the available space associated by the HR.

Finally, for O-Methylperezone (3), the HR in DMSO is lower than that measured for $\mathbf{1}$, as expected by the lack of solvent association through hydrogen bond. Again, a single molecule fits to the experimental HR.

The DOSY results preclude the presence of a noticeable amount of dimer entities. The experimental HRs are in very good agreement with the existence of a major presence of one single molecule of solute, associated or not to the solvent, depending on its chemical nature. Therefore, the observed nOes mainly arise from intramolecular interactions and take place at proton-proton distances even above $7 \AA$.

\section{Conclusions}

Real small nOe's or artifacts? In this case the relevant sources for artifacts are, spin diffusion, subtraction artifacts and accidental irradiation of close signals. According to the results here presented, these factor are not relevant for our observations. nOe's between hydrogen atoms located at distances longer than $6 \AA$ have been observed for a variety of small molecules with a common quinone-like framework. The nOe signals under study do not suffer changes when the concentration is modified and are maintained using different samples. Also, the signals do not change with neither the chemical shift nor the multiplicity and are not affected by the use of different instruments at different frequencies and temperatures. The change of solvents and mixing times do not alter the small nOe observed, although some changes in intensities were observed.

Although there was a distinct possibility that the observed nOes could be originated by the formation of dimers, the presence of association in large extent was discarded by dilution experiments and by using DOSY experiments. 
From the structural perspective, our results confirm the existence of folded conformers for perezone in contrast with previous reports using NMR data and vibrational circular dichroism $[19,20]$.

The information presented in this study is relevant for structural analysis, although care should be taken when directly interpreting the observed nOes for certain types of molecules without a quantitative analysis. This is an important finding with impact on the determination of conformation for molecules of this size and warrants further study on other systems.

Although the signals of interest are very small, of the order of $1 \%$ of a normal nOe, so a priori are considered artifacts originated by decoupling modulation, they maintain, properties that make them interesting and give them coherence as interpretable signals.

\section{Experimental Section}

NOESY 1D experiments were done using a recycle delay of $1 \mathrm{~s}$, acquisition time $2 \mathrm{~s}$ and the number of transients 2048 for concentrated samples and 6144 for diluted samples. Most of the NOESY 1D experiments were performed at $298 \mathrm{~K}$ on a VNMRS $500 \mathrm{MHz}$ spectrometer equipped with ID-PFG $5 \mathrm{~mm}$ probe with z-gradient accessory. Selective 1D NOE spectra were recorded using the DPFGSE technique using the Varian standard pulse sequence NOESY 1D included in the manufacturer's software. A standard Gaussian shaped pulse was used for the excitation pulse. The operating software automatically calculated the length and power of the pulse based on the peak integration area of the signal that was irradiated. For dilute solutions ( $5 \mathrm{mg}$ of perezone dissolved in $0.75 \mathrm{ml}$ of solvent) the number of transients was about 6144 and for concentrated samples $(25 \mathrm{mg}$ of perezone dissolved in $0.75 \mathrm{ml}$ of solvent) was about 2048 .

The selnogp5.cga experiments were performed at $293 \mathrm{~K}$ on a Brucker Avance IIIHD 700MHz spectrometer equipped with a BBI $5 \mathrm{~mm}$ probe with z-gradient accessory. Selective 1D nOe spectra were recording using the Brucker standart pulse sequence selnogp5.cga provided by manufacturer's software. Experiments were done using a recycle delay of $2 \mathrm{~s}$, acquisition time $4 \mathrm{~s}$ and the number of transients 3072 for degassed samples $0.02 \mathrm{M}$.

\section{Synthetic procedures}

Perezone (1) (2-(1,5-dimethyl-4-hexenyl)-3-hydroxy-5-methyl-1,4-benzoquinone) was isolated as is described [11] obtaining golden-yellow leaflets, $\mathrm{mp} 104-106^{\circ} \mathrm{C}$.

Synthesis of 2-(1,5-dimethyl-4-hexenyl)-3-methoxy-5-methyl-1, 4-benzoquinone (3).

To a solution of $1.9 \mathrm{~g}(0.023 \mathrm{~mol})$ of perezone in $70 \mathrm{ml}$ of acetone was added $5.35 \mathrm{~g}(0.115 \mathrm{~mol})$ of potassium carbonate and $1.84 \mathrm{ml}$ $(0.05 \mathrm{~mol})$ of dimethyl sulfate. The reaction was stirred for $3 \mathrm{~h}$ followed by addition of water and extracted with $\mathrm{CH}_{2} \mathrm{Cl}_{2}$. The organic phase was washed with water and brine and evaporated under vacuum. The residue was purified by chromatography $\left(\mathrm{SiO}_{2}, 90: 10\right.$ hex-AcOEt) afforded a yellow oil (yield $\left.96 \%\right) .{ }^{1} \mathrm{H}$ NMR $\left(500 \mathrm{MHz}, \mathrm{CDCl}_{3}, 25^{\circ} \mathrm{C}, \mathrm{TMS}\right) \delta 1.16(\mathrm{~d}, 3 \mathrm{~J}=7.2 \mathrm{~Hz}, 3 \mathrm{H}$, H9), 1.53 (3H, s, H15), 1.57, $1.73(2 \mathrm{H}, \mathrm{m}, \mathrm{H} 10), 1.64(3 \mathrm{H}, \mathrm{s}$, H14), $1.8(2 \mathrm{H}, \mathrm{m}, \mathrm{H} 11), 2.0\left(3 \mathrm{H}, \mathrm{d},{ }_{3} \mathrm{~J}=1.5 \mathrm{~Hz}, \mathrm{H} 7\right), 3.09(1 \mathrm{H}$, $\mathrm{m}, \mathrm{H} 8), 3.94(3 \mathrm{H}, \mathrm{s}, \mathrm{OMe}), 5.06(1 \mathrm{H}, \mathrm{m}, \mathrm{H} 12), 6.5(1 \mathrm{H}, \mathrm{q}, \mathrm{H} 5)$. ${ }^{13} \mathrm{C}$ NMR $\left(\mathrm{CDCl}_{3}, 125 \mathrm{MHz}\right) \delta 188(\mathrm{C} 4), 184.2(\mathrm{C} 1), 156.3$ (C2), 143.3 (C6), 136.8 (C3), 133.7 (C5), 131.5 (C13), 124.4 (C12), 60.8 (OMe), 34.7 (C10), 29.7 (C8), 26.7 (C11), 25.6 (C14), 18.9 (C9), 17.6 (C15), 15.1 (C7). MS (EI) m/z 262, 247, 219, 181, 166, 69. IR $\left(\mathrm{cm}^{-1}\right)$ 2963, 2930, 2858, 1654, 1599. HRMS (ESI) calcd for $\mathrm{C}_{16} \mathrm{H}_{23} \mathrm{O}_{3}[\mathrm{M}+\mathrm{H}]^{+} ; 263.16472$, found 263.16510 .

Synthesis of 2-(3',7'-dimethyl-6'-octenyl)-5-methyl-3,4-methylenedioxy anisole (6).

n-butyllithium ( $3.75 \mathrm{ml}$ of $1.6 \mathrm{M}$ solution in hexane) was added to a cold $\left(0^{\circ} \mathrm{C}\right)$ solution of 5-methyl -3,4-(methylenedioxy) anisole $(0.35 \mathrm{~g}, 2.14 \mathrm{mmol})$ in dry THF $(10 \mathrm{ml})[21]$. The reaction mixture was stirred at $0^{\circ} \mathrm{C}$ for $10 \mathrm{~min}$ and then at room temperatura for $4 \mathrm{~h}$. the mixture was cooled again to $0^{\circ} \mathrm{C}$ and 1-bromo-3,7-dimethyl-6-octene $(0.5 \mathrm{~g}, 2.3 \mathrm{mmol})$ was added dropwise [22]. The reaction was quenched with $\mathrm{NH}_{4} \mathrm{Cl}$ and extracted with $\mathrm{CH}_{2} \mathrm{Cl}_{2}$ (x3). The organic phase was washed with water and brine and evaporated under vacuum. The residue was purified by chromatography $\left(\mathrm{SiO}_{2}, 90: 10\right.$ hex-AcOEt $)$ afforded a yellow oil (yield 54\%). ${ }^{1} \mathrm{H}$ NMR $\left(500 \mathrm{MHz}, \mathrm{CDCl}_{3}, 25^{\circ} \mathrm{C}\right.$, TMS) $\delta 0.93\left(3 \mathrm{H}, \mathrm{d},{ }_{3} \mathrm{~J}=10 \mathrm{~Hz}, \mathrm{H} 4^{\prime}\right), 1.18\left(2 \mathrm{H}, \mathrm{m}, \mathrm{H} 5^{\prime}\right), 1.18$ $\left(2 \mathrm{H}, \mathrm{m}, \mathrm{H} 5^{\prime}\right), 1.39$ (3H, m, H2' $\left.{ }^{\prime} \mathrm{H}^{\prime}\right), 1.6\left(3 \mathrm{H}, \mathrm{s}, \mathrm{H} 10^{\prime}\right), 1.68$ $\left(3 \mathrm{H}, \mathrm{s}, \mathrm{H9} 9^{\prime}\right), 1.98\left(2 \mathrm{H}, \mathrm{m}, \mathrm{H6} 6^{\prime}\right), 2.19(3 \mathrm{H}, \mathrm{s}, \mathrm{H} 7), 2.53(2 \mathrm{H}, \mathrm{m}$, $\left.\mathrm{H} 1^{\prime}\right), 3.74(3 \mathrm{H}, \mathrm{s}, \mathrm{OMe}), 5.11\left(1 \mathrm{H}, \mathrm{t},{ }_{3} \mathrm{~J}=15 \mathrm{~Hz}, \mathrm{H} 7^{\prime}\right), 5.87(2 \mathrm{H}$, $\left.\mathrm{s}, \mathrm{OCH}_{2} \mathrm{O}\right), 6.11(1 \mathrm{H}, \mathrm{s}, \mathrm{H} 6) \cdot{ }^{13} \mathrm{C} \mathrm{NMR}\left(\mathrm{CDCl}_{3}, 125 \mathrm{MHz}\right)$ 814.79 (C7), 17.58 (C10'), 19.49 (C4'), 22.26 (C9'), 25.5 (C1'), 25.7 (C6'), 32.48 (C3'), 36.14 (C2'), 36.82 (C5'), 56.28 (OMe), $100.49\left(\mathrm{OCH}_{2} \mathrm{O}\right), 104.68(\mathrm{C} 6), 112.03(\mathrm{C} 2), 114.95$ (C5), 125.14 (C7'), 130.85 (C8'), 139.37 (C4), 145.81 (C3), 153.0 (C1). IR $\left(\mathrm{cm}^{-1}\right) 1211,1427,1460,1492,1656,2868$, 2924, 2956. EM (E.I) m/z 304, 219, 179, 166. HRMS (ESI) Calcd For $\mathrm{C}_{19} \mathrm{H}_{29} \mathrm{O}_{3}[\mathrm{M}+\mathrm{H}]^{+}$305.21167, found 305.21075.

\section{Acknowledgements}

The authors are grateful to Luis Velasco, Javier Pérez-Flores, Alfredo Toscano, María del Rocío Patiño Maya for technical assistance, to Prof. Anklin Clemens (Bruker BioSpin Corp.) by the reproduction of some NMR confirmative experiments, to Dirección de Cómputo y de Tecnologías de Información y Comunicación de la Universidad Nacional Autónoma de México, via Grant SC14-1-I-70, to Consejo Nacional de Ciencia y Tecnología (CONACYT) for financial support via Grant 165614, and to Dirección General de Asuntos del Personal Académico (DGAPA) via Grant No. IN-209416. E R-L is grateful to CONACYT-Mexico for the scholarship granted. 


\section{References}

1. Neuhaus D, Williamson M P. The Nuclear Overhauser Effect in Structural and Conformational Analysis. New York: John Wiley \& Sons, Inc.; 2000.

2. Poveda, A.; Vicent, C.; Penadés, S.; Jimenez-Barbero, J. Carbohydr. Res. 1997, 301, 5-10.

3. Stott, K.; Keeler, J.; Van, Q.N.; Shaka, A.J. J. Mag. Reson. 1997, 125, 302-324.

4. Butts C P, Jones C R, Towers E C, Flynn J L, Appleby L, Barron N, J. Org Biomol Chem. 2011; 9, 177-184. doi: 10.1039/ C0OB00479K.

5. Jones, C.R.; Butts, C.P.; Harvey, J.N Beilstein J Org Chem. 2011; 7: $145-150$.

6. Klika, K.D.; Cheriyamundath, S.; Raghavan, R.; Megha, K.B.; Banerji, A.; Owen, R.W.; Madassery, J. Tetrahedron Lett. 2014, $55,6550-6553$.

7. Kiharudin, L.M.; Bonvin, A.M.; Kaptein, R.; Boelens, R. J. Magn. Reson. 2003, 163, 228-235.

8. Cavanagh J., Fairbrother J., Palmer A., Skelton N., Rance M. Protein NMR Spectroscopy 2nd edition. 2006. Academic Press.

9. Rule, G.S. Fundamentals of Protein NMR Spectroscopy, 2005. Springer. New York.

10. a. Cuevas, G.; Martinez-Mayorga, K.; Fernández-Alonso, M. C.; Perrin C.L.; Jiménez-Barbero, J.; Juaristi, E.; López-Mora, N. Angew. Chem. Int. Ed. 2005, 44, 2630-2633. b. Cuevas, G.; Juaristi, E. J. Am. Chem. Soc. 2002, 124, 13088-13096. c. Martínez-Mayorga, K.; Juaristi, E.; Cuevas, G. J. Org. Chem. 2004, 69 7266-7276.

11. Roura-Perez, G.; Quiróz, B.; Aguilar-Martinez; M.; Frontana, C.; Solano, A.; González, I.; Bautista-Martínez, J.A.; Jimenez-Barbero, J.; Cuevas G. J. Org. Chem. 2007, 72, 1883-1894.
12. Río de la Loza, L., 1852. Discurso pronunciado por el catedrático de química médica de la Escuela de Medicina (November 23, 1852, 1, 131-137). In: Noriega, J.M. (Compiler), Escritos de Leopoldo Río de la Loza, Imprenta de Ignacio Escalante, México, 1911, pp. 94-100. Joseph-Nathan, P. Rev. Soc. Quim. Méx. 1974, 18, 226-241. Collera, O.; Aizpuru, R.; García, F.; Cuevas, G. Rev. Soc. Quim. Méx., 1994, 38, 35-40. Ramirez-Gualito, K.; Alonso-Rios, R.; Quiroz-García, B.; Rojas-Aguilar, A.; Diaz, D.; Jiménez-Barbero, J.; Cuevas, G. J. Am. Chem. Soc. 2009, 131, 18129-18138.

13. Di Bernardo, S.; Fato, R.; Casadio, R.; Fariselli, P.; Lenaz, G. FEBS Lett. 1998, 426, 77-80.

14. Hu, H.; Krishnamurthy K. J. Magn. Reson. 2006, 182, 173-177.

15. The selnogp5.cga is a pulse sequence for Bruker equipment and is written according to this publication: Stott, K.; Stonehouse, J.; Keeler, J.; Hwang, T-L.; Shaka, A. J. J. Am. Chem. Soc. 1995, 117 (14), 4199-4200.

16. Aguilar-Martínez, M.; Bautista-Martínez, J. A.; Macías-Ruvalcaba, N.; González, I.; Tovar, E.; Marín del Alizal, T.; Collera, O.; Cuevas, G. J. Org. Chem., 2001, 66, 8349-8363.

17. Cabrita, E.J.; Berger, S. Magn. Reson Chem. 2001, 39, S142-S148.

18. Marenich, V.; Cramer, C. J.; Truhlar, D.G. J. Phys. Chem. B, 2009, 113 6378-96.

19. Zepeda, L.G.; Burgueño-Tapia, E.; Pérez-Hernandez, N.; Cuevas, G.; Joseph-Nathan, P. Magn. Reson. Chem. 2013, 51, 245-250.

20. Burgueño-Tapia, E.; Cerda-García-Rojas, Joseph-Nathan, P. Phytochemistry 2012, 74, 190-195.

21. Sánchez, I. H.; Mendoza, S.; Calderón, M.; Larranza, M.; Flores, H, J. Org. Chem. 1985, 50, 5077-5079.

22. Newman, M.; Wotiz, J, J. Am. Chem. Soc. 1949, 71(4), 12921297. Compound was prepared from $\beta$-citronellol. 